\title{
2 C-Reactive Protein for Antibiotic Use in COPD 3 Exacerbations
}

4 Jan Y. Verbakel, M.D., Ph.D.

5 Ann Van den Bruel, M.D., Ph.D.

6 University of Leuven (KU Leuven)

7 Leuven, Belgium

8 jan.verbakel@kuleuven.be

9 Matthew Thompson, M.D., Ph.D.

10 University of Washington

11 Seattle, WA

12 To the Editor: Butler et al. have shown that CRP point-of-care testing can help

13 reduce antibiotic use in ambulatory care patients with COPD exacerbations.

14 Although baseline antibiotic use was high in the trial, the use of CRP point-ofcare testing resulted in reductions in use, as has been the case in trials involving patients with acute bronchitis. [n contrast with a Cochrane review in which therapeutic failure was more frequent in patients who did not receive treatment with antibiotics, 2 Butler et al. found no evidence of harm. However, the robust evidence for the role of CRP point-of-care testing in antibiotic stewardship has resulted in its adoption in ambulatory settings around the world\{sa2q1\}. In the United States, for example, where inappropriate antibiotic prescribing remains particularly high, CRP point-of-care testing remains unavailable in ambulatory settings, as does testing for similar biomarkers. This situation is quite different from that in several European countries where point-of-care CRP testing has 25 been adopted. The variability in adoption calls for more evidence of its benefit, , $^{n}$ 26 such as cost-benefit analyses that could lead to investment by manufacturers of 7 diagnostic tools and to reimbursement by health care payers.

Butler et al. provide the evidence that clinicians and their patients are seeking.] Deploying point-of-care CRP testing, together with improved training in communication skills, is paramount if antibiotic stewardship in ambulatory care is to be taken seriously.

Conflict

No potential conflict of interest relevant to this letter was reported.

\footnotetext{
References

1. Nerbakel JY, Lee JJ, Goyder C, et al. Impact of point-of-care C reactive protein in ambulatory care: a systematic review and meta-analysis. BMJ Open 2019;9(1):e025036. [PMID: 30782747]

2. Vollenweider DJ, Frei A, Steurer-Stey CA, Garcia-Aymerich J, Puhan MA. Antibiotics for exacerbations of chronic obstructive pulmonary disease. Cochrane Database Syst Rev 2018;10:CD010257. [PMID: 30371937]

3. Draft Health Technology Assessment of C-reactive protein point-of-care testing to guide antibiotic prescribing for acute respiratory tract infections in primary care settings. Cork, Ireland: Health Information and Quality Authority, January 2019 (https://www.hiqa.ie/sites/default/

files/2019-02/C-reactive-protein-point-of-care-testing-HTA-for-Public-Consultation.pdf). 4. Verbakel JY, Turner PJ, Thompson MJ, et al. Common evidence gaps in point-of-care diagnostic test evaluation: a review of Horizon Scan reports. BMJ Open 2017;7:e015760. [PMID: 28864692] 5. Hardy V, Thompson M, Keppel GA, et al. Qualitative study of primary care clinicians' views on point-of-care testing for $\mathrm{C}$-reactive protein for acute respiratory tract infections in family medicine.
} 
BMJ Open 2017;7(1):e012503. [PMID: 28122829]

\section{Queries}

sa2q1. AU: Preceding sentence OK as edited? 